\title{
Iron-Based Amorphous Metals-An Important Family of High-Performance Corrosion-Resistant Materials
}

\author{
Foreword
}

The possibility of achieving outstanding corrosion resistance with compositionally modified iron-based amorphous metals was recognized several years ago, with substantial progress made recently in the realization of this potential. Due to their unique combination of properties, these high-performance corrosion-resistant materials should find widespread use in applications such as heavy equipment manufacture, enhanced transportation infrastructure including steel reinforcement bars for concrete and steel bridges, the safe storage, transportation and disposal of spent nuclear fuel, and national defense. These materials have been shown to have excellent wear hardness with exceptional resistance to abrasion and gouges, and corrosion resistance better than that of conventional stainless steels and comparable to that of Ni-based alloys. Since their discovery, new alloy compositions have been designed and synthesized that have led to improved stability at high temperatures, well above $500{ }^{\circ} \mathrm{C}$. In addition, the boron content that is present in these new formulations provides excellent neutron absorbing characteristics that make them suitable for criticality control applications. Despite the progress made in high-performance corrosion-resistant metals (HPCRMs), there continues to be a need to master their properties, improve their quality, and quantify their performance so that their use as integral components of structural materials can be considered with a high level of confidence.

To address this challenge, a symposium was held during the Materials and Science and Technology Conference and Exhibition in Detroit, Michigan, MS\&T07 to bring together experts in the field. The MS\&T Symposium on the "IronBased Amorphous Metals - An Important Family of High-Performance Corrosion-Resistant Materials" focused on the corrosion resistance achievable with thermal spray coatings of iron-based amorphous metal formulations. In some environments, these materials appear to be as corrosion resistant as stainless steels and Ni-Cr-Mo alloys. Their exceptional hardness can provide excellent abrasion and wear resistance, thereby enabling applications in earth excavation, drilling, and tunnel boring. Their high boron content may enable them to serve effectively as neutron absorbers in nuclear energy systems. Large areas and prototypes have been successfully coated with these materials, with thicknesses of approximately $1 \mathrm{~cm}$. This symposium provided a forum for the systematic and integrated presentation of new scientific results on alloy design and composition, materials synthesis, thermal stability, corrosion resistance, environmental cracking, mechanical properties, damage tolerance, radiation effects, and important potential applications. During the final session of the symposium, a panel discussion that involved all the participants was organized to review and discuss the research needs for facilitating high-volume applications of Fe-based amorphous metals. Representation was crosscutting and included government sponsors, national laboratories, universities, and industry, and was international in scope. Of the 38 invited and contributed papers accepted and presented at this symposium, 7 papers were selected based on the recommendations from the reviewers and session chairs for peer review and inclusion in this special section of Metallurgical and Materials Transactions A. The papers range in subject from overview and fundamental properties, to processing for optimum coating, hardness, viscosity, and corrosion properties, and finally potential application of thermal sprays in the nuclear industry.

We hope that this special selection of representative papers from the symposium will provide scientists, engineers, and students with a perspective of what the experts in this field feel is required to stimulate continuous development and applications of a promising class of high-performance amorphous materials and, at the same time, cause a renewed interest in fundamental work on metallic glasses and their relation to complex crystals.

N.B.: This article is based on a presentation made at the "Iron-Based Amorphous Metals-An Important Family of High-Performance Corrosion-Resistant Materials" Symposium as part of the MS\&T07 Conference and Exhibition in Detroit, Michigan, September 16-20, 2007, under the auspices of the American Ceramics Society (ACerS), the Association for Iron and Steel Technology (AIST), ASM International, and The Minerals, Metals and Materials Society (TMS), and with the sponsorship of the Lawrence Livermore National Laboratory.

Joseph C. Farmer and Patrice E.A. Turchi Lawrence Livermore National Laboratory, Livermore, California

John H. Perepezko University of Wisconsin, Madison, Wisconsin 